\title{
DIGITALCOMMONS
}

@WAYNESTATE-

Wayne State University

3-30-2020

\section{Methodology Matters: Designing a Pilot Study Guided by Indigenous Epistemologies}

\author{
Sandra A. Juutilainen \\ Ryerson University \\ Melanie Jeffrey \\ University of Toronto \\ Suzanne Stewart \\ University of Toronto
}

Follow this and additional works at: https://digitalcommons.wayne.edu/humbiol_preprints

\section{Recommended Citation}

Juutilainen, Sandra A.; Jeffrey, Melanie; and Stewart, Suzanne, "Methodology Matters: Designing a Pilot Study Guided by Indigenous Epistemologies" (2020). Human Biology Open Access Pre-Prints. 162. https://digitalcommons.wayne.edu/humbiol_preprints/162

This Article is brought to you for free and open access by the WSU Press at DigitalCommons@WayneState. It has been accepted for inclusion in Human Biology Open Access Pre-Prints by an authorized administrator of DigitalCommons@WayneState. 


\section{Methodology Matters: Designing a Pilot Study Guided by Indigenous Epistemologies}

Sandra A. Juutilainen, ${ }^{*}$ Melanie Jeffrey,2 and Suzanne Stewart3

IIndigenous Health and Nutrition, School of Nutrition, Ryerson University, Toronto, Ontario, Canada.

${ }_{2}$ Centre for Indigenous Studies and Human Biology Program, Faculty of Arts and Science, University of Toronto, Toronto, Ontario, Canada.

3Waakebiness-Bryce Institute for Indigenous Health, Dalla Lana School of Public Health, University of Toronto, Toronto, Ontario, Canada.

*Correspondence to: Sandra A. Juutilainen, Indigenous Health and Nutrition, School of Nutrition, Ryerson University, 288 Church Street, Room DCC-601, Toronto, Ontario, Canada, M5B 2K9. E-mail: sandra.juutilainen@ @ryerson.ca.

Short Title: Designing a Pilot Study Guided by Indigenous Epistemologies

KEY WORDS: INDIGENOUS EPISTEMOLOGY, INDIGENOUS METHODOLOGY, COMMUNITY-BASED RESEARCH, SPINAL CORD INJURY, SPINAL CORD

REGISTRIES, MIXED-METHODS, ETHICAL INDIGENOUS RESEARCH, FIRST NATIONS, ONTARIO, CANADA. 


\begin{abstract}
Indigenous individuals and communities have historically and continuously had negative experiences with Western health care and biomedical research. To rebuild trust and mitigate power structures between researchers and Indigenous Peoples, researchers can adopt Indigenous epistemologies in methodologies, such as non-hierarchical approaches to relationship. This paper shares models developed to bridge Indigenous epistemologies with Western qualitative and quantitative research methods and demonstrates how these epistemologies can be used to guide the development of pilot study.
\end{abstract}

Pre-print version. Visit http://digitalcommons.wayne.edu/humbiol/ after publication to acquire the final version. 
In Canada, Indigenous Peoples are those of three distinct cultural groups: First Nations, Métis and Inuit. Canada generally has excellent health care data, but too often, data depicting Indigenous health is deficit-based. Disparities exist between Indigenous and non-Indigenous health, but without addressing cultural, social, and broad environmental contexts of these differences, underlying causes of these health disparities and policy initiatives affecting them cannot be understood. Currently in Canada, Indigenous governments and organizations are undergoing health transformations, re-envisioning what their health care systems could be like to best serve their diverse communities, both large urban communities and small rural/remote communities.

Unmet health care needs are common in First Nations populations both on and off reserves (Wilk, Maltby, and Phillips 2018), yet the majority of statistics regarding Indigenous populations continue to perpetuate a narrative of dependency rather than areas of service provision improvement. Studies that are Indigenous focused usually note high injury rates among all Indigenous demographics. For example, Indigenous Canadians are particularly at risk for trauma-related injuries (Karmali et al. 2005) and are vulnerable to sustaining more severe injuries following a motor vehicle accident (Wearmouth and Wielandt 2009). Although these studies are important, the underlying causes of these differences were not explored. No studies to date have reported the strengths and resiliencies of Indigenous persons with traumatic spinal cord injury (TSCI), or their experiences. This commentary presents how our methodology de-centres the prototypical "5 D's" of Indigenous data: disparity, depravation, disadvantage, dysfunction and difference. Instead, our process includes an emphasis on positive aspects of individuals and communities to build a strengths-based, comprehensive and culturally appropriate dataset 
(Walter and Suina 2019). In addition, we share two epistemologies/methodologies that incorporate Western research into Indigenous knowledge and value systems.

\section{Ethical Considerations}

Many Indigenous scholars note that imbalanced power relationships between researchers and Indigenous persons results in erroneous interpretations of Indigenous experiences (BrantCastellano 2004; Corntassel and Gaudy 2014; Keskitalo 1976; Kuokkanen 2006; Kovach 2009; Snarch 2004; Tuhiwai Smith 1999, 2012), and have discussed colonialism within research as an extractive process that benefits researchers but not communities. Extractive research processes are not only irrelevant but unethical (Corntassel and Gaudy 2014). From the "discovery" of aspirin from willow bark to academic career-building without Indigenous community benefit to the Canadian government's ongoing sale of Indigenous health data to pharmaceutical companies, Indigenous data has been used unethically and for purposes which were not consented to by Indigenous Peoples (First Nations Information Governance Centre 2020).

The legacy of colonial relationships between the academy and Indigenous communities continues to manifest itself in how knowledge is currently produced, perceived and what is considered valid for qualitative (Kuokkanen 2006) and quantitative (Kuhn 1970) studies. Qualitative data has been embraced almost to the exclusion of the quantitative in Indigenous research. This is not surprising given very troubling relationships between Indigenous persons and the cultures of Western science and biomedicine, and purely quantitative health statistics that do not reflect Indigenous values (Smylie and Firestone 2015). A lack of meaningful quantitative data is particularly troubling since it forms the basis of policy change. To engage in more 
relevant and ethical research, researchers must question assumptions in disciplines and academia at large.

Working in a space between cultural and academic ethical principles involves redefining and rethinking research relationships (Bull 2010; Edwards et al. 2008; Vogel 2015). Indigenous worldviews are relational in nature (Hart 2010; Kovach 2009; Wilson 2008); a key aspect of Indigenous research involves ethical considerations of both individual and community level consent. Community consent is a process that occurs after meaningful community consultation; it does not preclude the need for individual consent (Dickert and Sugarman 2005).

The United Nations Declaration on the Rights of Indigenous Peoples (UNDRIP) specifies the rights of Indigenous Peoples to self-determination and their collective right to exercise control over expressions of their cultural heritage and intellectual property (United Nations 2007). The main tenets of the framework for developing ethical guidelines and policy for Indigenous research worldwide are directly linked to self-determination. We provide three examples of concepts stemming from asymmetrical research relationships of the past have been developed to improve research outcomes and re-build trust between Indigenous communities and researchers.

First, research praxis provides a space for cross-cutting concepts of self-determination and relationality in a Maori context. The original Treaty of Waitangi between the British Crown and Maori Rangatira (chiefs) establishes principles of partnership, participation, and protection. Researcher actions should align with rights, roles, and responsibilities implied in the Treaty of Waitangi, including potential risks, benefits and outcomes of research. Research should take place in a framework of "Maori values of wahkapono (faith), tumanako (aspirations), and aroha (awareness)" (Hudson et al. 2010 p. 164). Similarly, Native Hawaiian protocols in research 
praxis from project identification through to dissemination of results are firmly rooted in ongoing communication with community to ensure the project meets community needs. Ongoing engagement, data ownership at the community level and community benefit circle back to the principles, actions and values of the "Waimānalo Pono Research Hui: Establishing Protocols and Rules of Engagement to Promote Community-Driven and Culturally-Grounded Research" in self-determined research projects (Kealuana et al. 2019).

Secondly, the Nordic dialogue regarding Sami research ethics includes Nordic Sami researchers and leading Sami politicians (Porsanger 2008). However, only in Norway has the dialogue come to the national level (The National Committee for Research Ethics in the Social Sciences and the Humanities 2002). Collaborations regarding Sami research ethics have predominantly taken place in Norway; although momentum among Sami academic and selfgovernment institutions in Finland and Sweden is occurring, collaborations have not been implemented (Juutilainen and Heikkilä 2016). A recent Norwegian report, "Proposal for ethical guidelines for Sami health research and research on Sami human biological material" highlighted principles that would ensure the integrity and recognition of Sami Peoples in research: Principles of respect, responsibility, reciprocity, self-determination, and equal status (Samediggi 2018).

Lastly, in Canada, ethical Indigenous research requires adhering to principles of OCAP® (Ownership, Control, Access, Possession), an acronym used to describe research relationships whereby the research agenda, data, and outcomes (in whatever form) will be owned, controlled, accessed and possessed by the Indigenous community or their designated stewards (FNIGC 2020). OCAP® is self-determination applied to research. It is a political response to persistent colonial approaches to research and information management (Snarch 2004). The principles of OCAP® have guided researchers working with First Nations, Inuit and Métis communities and 
have informed the development of national Indigenous research ethics policies within Canada (Tri-Council Policy Statement 2 2018). Communities, not researchers, decide the direction of the research study, who can access the data and how it will be used. Communities are viewed as research collaborators, not as research subjects or participants. Community collaborators define the nature of the research questions, methods, benefits to the community, and how results are communicated. The four R's: respect, responsibility, relevance, and reciprocity, provide a research framework for understanding and engaging with First Nations in a culturally appropriate and safe manner (Kirkness and Barnhardt 1991).

\section{Listening Well}

Indigenous research in Canada has been largely qualitative to the exclusion of the quantitative, which can limit the evidence base used to make policy decisions (Walter and Suina, 2019). It is well-established that Indigenous persons in Canada experience poorer health outcomes than the general population (Allan \& Smylie, 2015; National Collaborating Centre for Aboriginal Health 2013; Aboriginal Healing Access Centres and Aboriginal Community Health Centres 2016).

Insights on how to improve these health outcomes can only be known by speaking with Indigenous individuals and communities (Bull 2010). Indigenous research is by nature interdisciplinary in the context of Western academics. Health care registries and datasets informed by both qualitative and quantitative data are needed to understand health outcomes and subsequently, enact meaningful policy change.

A key starting point for this process is for researchers to respect Indigenous knowledge systems and accept input from community partners and individual participants. This process can make researchers uncomfortable, as Western knowledge systems are considered one way of 
knowing, which in the authors' experiences, may not necessarily be the best way of knowing when working with Indigenous peoples. Contrary to academic disciplinary training, researchers must put aside notions of medical and Western academic expertise when engaging in ethical research with Indigenous Peoples. Furthermore, to impose research strategies or health policy recommendations without involving Indigenous leadership and communities is a form of colonization (Allan and Smylie 2015; Walter and Suina 2019). Researchers must listen to and respect what Indigenous Peoples choose to share and why they chose to share it.

To listen well, researchers must engage communities to direct research questions and agendas. It is imperative that researchers, Indigenous and non-Indigenous, reflect critically on their own motivations and engage in ongoing consent with collaborators throughout the research process [Figure 1, blue text]. At many institutions, in order to mitigate harm, separate ethical review protocols exist for working with Indigenous communities and individuals. Researchers can ask an applied health research question of general population linked health care datasets relatively easily, by showing academic and health merit to the research question. Yet the ethics are complicated when working with Indigenous populations. For First Nations Peoples who are Status Indians (or the Canadian Federal Government Indian Act's imposition of official identity on First Nations Peoples), access to their health care data is governed by the Chiefs of Ontario (COO). Researchers must show an awareness of the principles of Indigenous research and significant community consultation for COO to allow access to these data for applied health research questions. In Ontario, the health data of First Nations persons who are recognized as Status Indians are administratively separable from the general population. For First Nations persons not considered Status Indians, their data is not administratively separable from the general population, is not governed by $\mathrm{COO}$, and self-identification on treatment intake forms is 
the only way they are recognized as an Indigenous person within existing spinal registries. This is a complexity of registries and linked data sets in Indigenous research. Existing health care datasets and registries only identify Indigenous persons who are Status Indians, leaving many Indigenous persons uncounted. Furthermore, Indigenous persons may choose not to self-identify on treatment intake forms due to actual and perceived systemic racism in Canadian healthcare. Since Canada does not track race-based statistics in health care datasets and Indigenous identities are far broader than Status Indians as defined by the Government of Canada's Indian Act, the ability to plan effective health care delivery and policies are limited.

A second key element of ethical Indigenous research is that methodological choices must centre on Indigenous communities and reflect the communities' priorities and interests. For the authors, that meant reframing a research query from "How can we build an Indigenous TSCI registry?" to "What are the characteristics of a meaningful and relevant TSCI registry for Indigenous persons?" To engage in relational ways of knowing and being, researchers must be cognizant of their positionality. Research practices have targeted Indigenous People worldwide to further interests of colonial control; this continues in well-intentioned research that is culturally insensitive and does not meet needs and protocols of communities. Researchers in academia have power and privilege, including when they are working in community-based models. To understand what constitutes knowledge and how it is gathered and shared, we must constantly re-examine values in the community and academic setting (Cochran et al. 2018). Researchers also need to be aware that many communities are over-engaged or exhausted by continuing requests to participate in health studies, and that cultural sensitivity and research questions emerging from community-identified needs can mitigate these stressors (Maar et al. 2011). 


\section{This Pilot Study}

In the past, human biology focused on the physical aspects of health. Today it is clear that the interactions between and within environmental, spiritual, emotional and mental health significantly impact physical health, and vice versa (Burke et al. 2016; Berger et al. 2017; Braaf et al. 2017). Trusting and navigating Western biomedical care generally is problematic for many Indigenous persons. Facilitators and barriers to healing journeys for First Nations individuals with TSCI, as well as their families, caregivers, and communities are unknown, as are the relationships between TSCIs and culturally safe supports for physical, social, spiritual and emotional health. With the guidance of collaborators, our study will investigate these relationships.

Therefore, the objectives of the study include: Understanding the current picture of TSCI among First Nations populations in Ontario with regards to their health care experiences, services and supports via stakeholder interviews; using qualitative data to determine priorities and direction for quantitative analysis of existing registries and datasets; to identify aspects of a cohesive and meaningful spinal registry for First Nations persons living with TSCI and their caregivers in Ontario in a wholistic, culturally appropriate manner; and to address barriers and emphasize strengths in local contexts.

Currently, there are no national Canadian registries of incidence and prevalence of TSCI for the general population, only estimates of TSCI rates in the provinces (Noonan et al. 2012), which may include Indigenous self-identification on treatment intake forms at spinal centres in major urban hospitals. Despite high costs associated with traumatic and non-traumatic spinal cord injuries, there is a paucity of incidence and prevalence data in Canada (Noonan et al. 2012), 
particularly among Indigenous Peoples. McCammon and Ethans (2013) acknowledge that the trend of higher incidence rates of spinal cord injuries among the First Nations population in Manitoba is of concern. In Saskatchewan, motor vehicle accidents are a primary cause of TSCI for both the general population and Indigenous persons. In the general population, the secondmost common cause of TSCI is falls, but for Indigenous persons, the second most common cause of TSCI is assault (Ahmad et al. 2020, in press).

Using the quantitative health care data measurements in Ahmad et al. (2020), our study will inform spinal cord registries and a proposed database of neurological conditions for First Nations persons across Canada (Native Women's Association of Canada 2013). However, these medical diagnostic and data registry codes do not capture the nuances of TSCI, and how it is experienced by Indigenous persons in Canada. Hence, the authors are listening to First Nations persons in northern Ontario living with TSCI $(\mathrm{n}=10)$, their caregivers $(\mathrm{n}=10)$ and care providers $(n=10)$ throughout the treatment journey from initial injury to rehabilitation to community, to identify key measures of, and barriers to, holistic wellbeing. Qualitative interviews will inform research priorities in quantitative, linked datasets [Figure 1]. This process includes iterative consultations with First Nations persons and communities.

Despite significant gaps in the continuum of care, strategies are used by the study's collaborators to piece together a person's physical treatment journey using available quantitative data [Figure 1, box top right]. In both general population and Indigenous-specific data analysis, proxy measures and pathways identified by collaborators and qualitative research will be used to identify characteristics of physical, mental, emotional and spiritual wellbeing in First Nations persons living with TSCI to the extent possible with existing quantitative data [Figure 1, box bottom right]. These findings will be shared with stakeholders, and further proxy measures and 
data of priority for wellness will be identified and analysed [Figure 1, box bottom left] to the extent possible. The measures most meaningful and relevant to First Nations person living with TSCI will be the basis of a TSCI registry for First Nations persons [Figure 1, box top left].

\section{Indigenous Perspectives on Neurological Conditions: Implications for Our Study}

The Native Women's Association of Canada is one of the only resources about First Nations and neurological conditions across Canada and informs our study (2013). In this report, they identify spirituality as a coping mechanism for emotional, physical and mental impacts. Unmet spiritual needs made recovery more challenging, whereas being able to interact with traditional healers and Elders familiar with their culture and traditions helped persons adjust to and cope with their neurological conditions. Participants expressed that they would like Indigenous spiritual needs, such as smudging, sweats, and other ceremonies, to be accepted and encouraged within health care systems. Family could contribute significantly to positive or negative recovery processes. In the northern Ontario, participants described the long journey from home to attend medical appointments, in which they were sometimes alone for long periods of time, as a financial and social burden. The costs of transportation and accommodation were a barrier to accessing health care and other services. A lack of service providers, including physicians and homecare providers, was cited as another barrier to recovery and wellness (NWAC 2013).

The report also identified systemic barriers, such as policies that required medical forms completed by physicians to access social services. Poor quality and expensive foods from stores in contaminated areas compromised positive and protective factors associated with traditional foods and lifestyles. Environmental contamination was further associated with psychological stress such as fear, lack of control and helplessness (NWAC 2013). Recommendations made 
with the NWAC report are listed in Table 1. In addition to the NWAC report, consultation with the authors' collaborators revealed that hospital stays can be unnecessarily prolonged when First Nations patients are trying to obtain necessary equipment. In addition, much of the equipment and care covered by the Non-Insured Health Benefits (NIHB) program for Indigenous persons recognized by government as Status Indians is inadequate. Often, patients waiting for minor equipment items can prevent hospital discharge for weeks, causing a substantial increase in net cost for the system.

The effects of TSCI differs between geographies (urban, rural, remote) as well as within and between First Nations' cultures in Ontario. Surgical and rehabilitation spinal centres exist in the southern, more populous regions of Ontario where TSCI-specific datasets collect information from willing participants who may choose to self-identify as Indigenous on treatment intake forms. Our study's focus is on the vast regions of northern Ontario from Thunder Bay to Hudson's Bay, which have a higher proportion of First Nations persons and lack spinal centres and spinal registry data. In northern areas of Ontario, the less dense population across the region may preclude TSCI statistics in existing provincial health care datasets; in regions where there is a prevalence of less than 5 injuries, none would be reflected in linked datasets. TSCI cases may be missed entirely in rural or remote settings, a large omission given the substantial personal and healthcare costs associated with them (Krueger et al. 2013), including medical evacuation to appropriate facilities. These costs will be compounded by inadequate access to culturally safe healthcare (Bourassa et al. 2015).

After initial injury and rehab, subsequent readmissions for common (and largely preventable) comorbidities are also of concern. These are important data for optimal health care service delivery. For example, knowing the rates of urinary tract infection would allow for cost- 
benefit analysis. The study's collaborators have identified not having enough catheters as a problem; some people were forced to wash and reuse them, even in areas without potable water. One simple solution to prevent bladder infections from becoming life-threatening would be to give all persons living with TSCI "touch-free" catheters and urinary tract infection dipsticks through the NIHB and the provincial health care system. This would allow TSCI persons to monitor and maintain their urinary health more independently, and seek treatment for urinary tract infections in early stages before they become urgent health emergencies.

\section{Guiding Indigenous Epistemologies}

The significance of Indigenous epistemologies and worldviews is their non-hierarchical structures that embody a broader notion of health than traditional biomedicine. Conducting research using an Indigenous lens promotes the use of cultural protocols and re-centers marginalized knowledge in respectful ways, as well as relating to one another according to Indigenous ethical codes (Getty 2010). This starting point has strong cultural agency and reconfigures approaches to research that privilege the agency of all things relational (Martin 2017). It also attempts to unseat the power dynamics between Indigenous and Western ways of knowing.

Our approach was guided by epistemologies of Anishinaabe/Cree and Haudenosaunee First Nations in Ontario: The Medicine Wheel [Figure 1] and Two-Row Wampum [Figure 2], respectively. Utilizing Indigenous cultural frameworks ensures contextual reflection, whereby researchers must situate themselves and the Indigenous Peoples with whom they are collaborating in the research process. Emphasizing the respectful inclusion of Indigenous 
Peoples in the research process preserves self-determination and prioritizes of Indigenous ways of knowing (Drawson et al, 2017).

The medicine wheel has many teachings, but for the authors' pilot study, the wheel represents TSCI in an Indigenous perspective of wholistic health: An equal balance of physical, mental, emotional and spiritual health [Figure 1]. Data measures identified in qualitative research will be recommended for inclusion in future databases and will shape the analyses of existing data. Research processes guided by the Indigenous perspectives of wholistic health are indicated in boxes. Researchers must make iterative journeys around the wheel to remain ethically engaged with community (blue text). Initial concerns raised by collaborators are identified in circles. The use of this model is a way to co-construct meaningful and relevant measures with the study's collaborators, and as a guide for researchers' iterative reflections.

The Two Row Wampum (Kaswentha) may best be understood as a Haudenosaunee term embodying the ongoing negotiation of their relationship to European colonizers and their descendants; the underlying concept of Kaswentha emphasizes the distinct identity of the two peoples and a mutual engagement to coexist in peace without interference in the affairs of the other (Parmenter 2013) [Figure 2]. The two purple rows represent the Haudenosaunee and European nations and the three white rows in between embody the principles of peace, friendship and respect and provide instruction on how we are to engage with one another on matters of importance to both nations. However, the same principles of peace, friendship and respect can be applied to any relationship, in particular among researchers (Indigenous and non-Indigenous) who are working together to find solutions to issues identified by the community (Freeman 2015; Hill \& Coleman 2018). Academics have an opportunity to learn from community collaborators by centering Indigenous knowledges and ways of being from within their own philosophical 
contexts rather than assimilating the knowledge systems into Eurocentric worldviews (Hill and Coleman 2018).

Consultation with Indigenous Elders, Indigenous faculty and Indigenous persons is also central to the study's research framework. Considerations around non-hierarchical thinking included discussions of the equal value of Indigenous healing traditions and Western medicine along the care journey, and ensuring no person felt shame for preferring access to either or both healing modalities. Elders reiterated the importance of taking the time to listen to the knowledge shared from an Indigenous perspective and to be clear with participants about project outcomes. Participants are considered as collaborators in this study and their responses will help to inform barriers and facilitators to care for Indigenous persons living with TSCI, making a "soft moccasin path" for others to have an easier journey, and on a broader scale, inform community health transformation. A key aspect of this is understanding how participants are supported (or not) in their social environments. Lastly, it was reinforced that researchers need to go back to communities and show reciprocity in a tangible way by sharing research results via a social event to bring people together.

The authors also consulted with spinal cord injury non-government organizations and acute and chronic spinal cord injury researchers, surgeons and rehabilitation specialists affiliated with the University of Toronto and Thunder Bay Hospitals and Rehabilitation Centres. Working with collaborators who have pre-existing, respectful relationships with First Nations communities and individuals has facilitated the outreach to potential study participants across northern Ontario. Speaking with First Nations persons living with a TSCI, and their caregivers, as well as spinal cord injury healthcare service providers throughout the care journey (acute, rehabilitation and post-discharge) is necessary to identify barriers and facilitators to health care 
and wellness. Once established, these relationships need to be maintained beyond the scope of a single study. The results of the study will include suggestions for future data principles in spinal registries when working with First Nations persons that also align with larger community goals for health transformation. This relational approach will inform the creation of more comprehensive, culturally relevant spinal cord injury registries for First Nations Peoples in northern Ontario, with implications for Indigenous data sovereignty across Canada.

\section{Conclusion}

Indigenous communities worldwide are gathering strength. Their rights to self-determination are important predictors of health. This includes the right to determine what research questions are of interest to communities and how they should be investigated. To engage in relationality, researchers must understand that Indigenous knowledge systems must be valued and respected, not subsumed into a Eurocentric academic construct. Using Indigenous epistemologies can build trust, mitigate problematic hierarchical perspectives of knowledge and provide researchers and communities with models of research processes.

The authors' embarked on a dialogical process to develop research agendas and priorities that are community-driven and iterative. Continuing an iterative journey around the Medicine Wheel [Figure 1] and adhering to the principles of the Two-Row Wampum for relationship building [Figure 2] are essential to the research framework for this pilot project.

Received 9 August 2019; accepted for publication 4 March 2020. 


\section{Literature Cited}

Aboriginal Health Access Centres (AHAC) and Aboriginal Community Health Centres (ACHC). 2016. Aboriginal Health Access Centres and Aboriginal Community Health Centres: Report to Communities (2016). Toronto, ON: Alliance for Healthier Communities.

Ahmad, U. S., S. Humphreys, C. Rivers et al. 2019. Traumatic spinal cord injuries among Aboriginal and non-Aboriginal populations of Saskatchewan: A prospective outcomes study. Can. J. Surg. accepted.

Allan, B., and J. Smylie. 2015. First Peoples, Second Class Treatment: The Role of Racism in the Health and Well-Being of Indigenous Peoples in Canada. Toronto, ON: The Wellesley Institute.

Berger, M., A. Leicht, A. Slatcher et al. 2017. Cortisol awakening response and acute stress reactivity in First Nations People. Sci. Rep. 7:1-10.

Bonaparte, D. 2005. The Two Row Wampum Belt: An Akwesasne Tradition of the Vessel and Canoe. Originally published in The People's Voice on August 5, 2005. http://wampumchronicles.com/tworowwampumbelt.html.

Braaf, S., A. Lennox, A. Nunn et al. 2017. Social activity and relationship changes experienced by people with bowel and bladder dysfunction following spinal cord injury. Spinal Cord $55: 679-686$.

Brant Castellano, M. 2004. Ethics of aboriginal research. J. Aborig. Health 1:98-114.

Bull, J. R. 2010. Research with aboriginal peoples: Authentic relationships as a precursor to ethical research. J. Empir. Res. Hum. Res. Ethics 5:13-22.

Burke, N. N., C. Y. Fan, and T. Trang. 2016. Microglia in health and pain: Impact of noxious early life events. Exp. Physiol. 101:1,003-1,021. 
Canadian Institutes of Health Research, Natural Sciences and Engineering Research Council of Canada, and Social Sciences and Humanities Research Council. 2018. Tri-Council Policy Statement: Ethical Conduct for Research Involving Humans (TCPS2 2018). Ottawa, ON: Interagency Advisory Panel on Research Ethics and the Government of Canada.

Cochran, P. A. L., C. A. Marshall, C. Garcia-Downing et al. 2008. Indigenous ways of knowing: Implications for participatory research and community. Am. J. Public Health 98:22-27.

Corntassel, J., and A. Gaudry. 2014. Insurgent education and indigenous-centred research: Opening new pathways to community resurgence. In Learning and Teaching CommunityBased Research: Linking Pedagogy to Practice, C. Etmanski, B. L. Hall, and T. Dawson, eds. Toronto, ON: University of Toronto Press, 167-185.

Dickert, N., and J. Sugarman. 2005. Ethical goals of community consultation in research. Am. J. Public Health 95:1,123-1,127.

Drawson, A. S., E. Toombs, and C. J. Mushquash. 2017. Indigenous research methods: A systematic review. Int. Indig. Policy J. 8:1-25.

Edwards, K., C. Lund, and N. Gibson. 2008. Ethical validity: Expecting the unexpected in community-based research. Pimatisiwin 6:17-30.

First Nations Information Governance Centre. 2020. Fundamentals of OCAP®. Online training course. Akwesasne, ON: First Nations Information Governance Centre.

Freeman, B. M. 2015. The spirit of Haudenosaunee youth: The transformation of identity and well-being through culture-based activism. PhD diss., Wilfred Laurier University.

Getty, G. A. 2010. The journey between western and indigenous research paradigms. $J$. Transcult. Nurs. 21:5-14. 
Hart, M. A. 2010. Indigenous worldviews, knowledge, and research: The development of an indigenous research paradigm. J. Indig. Voices Soc. Work 1:1-16

Hill Sr., R. W., and D. Coleman. 2018. The Two Row Wampum-Covenant Chain tradition as a guide for indigenous-university research partnerships. Cult. Stud. Crit. Methodol. 19:339-359.

Hudson, M., M. Milne, P. Reynolds et al. 2010. Te Ara Tika: Guidelines for Māori Research Ethics: A Framework for Researchers and Ethics Committee Members. Grafton, NZ: Health Research Council of New Zealand. Published on behalf of the Pūtaiora Writing Group.

Juutilainen, S., and L. Heikkilä. 2016. Moving forward with Sámi research ethics: How the dialogical process to policy development in Canada supports the course of action for the Nordic countries. In Ethics in Indigenous Research: Past Experiences - Future Challenges, A.-L. Drugge, ed. Umeå, SE: Vaartoe - Center for Sami Research, 81-104.

Karmali, S., K. Laupland, A. R. Harrop et al. 2005. Epidemiology of severe trauma among status Aboriginal Canadians: A population-based study. CMAJ 172:1,007-1,011.

Keaulana, S., J. J. Chung-Do, I. Ho-Lastimosa et al. 2019. Waimānalo Pono Research Hui: Establishing protocols and rules of engagement to promote community-driven and culturally-grounded research with a Native Hawaiian community. Br. J. Soc. Work 49:1,023-1,040.

Keskitalo, A. I. 1976. Research as an Inter-Ethnic Relation. Social Science Research and Minority Society. Presentation at the Nordic Ethnographer Meeting, Troms $\varnothing$ 1974. In Acta Borelia, B Humanioria 13. Tromso Museum 1976. 15:42. 
Kirkness, V. J., and R. Barnhardt. 1991. First Nations and higher education: The four R's Respect, relevance, reciprocity, responsibility. J. Am. Indian Educ. 30:1-15.

Kovach, M. 2009. Indigenous Methodologies: Characteristics, Conversations, and Contexts. Toronto, ON: University of Toronto Press.

Krueger, H., V. K. Noonan, L. M. Trenaman et al. 2013. The economic burden of traumatic spinal cord injury in Canada. Chronic Dis. Inj. Can. 33:113-122.

Kuhn, T. S. 1970. The Structure of Scientific Revolutions, 2nd ed. Chicago, IL: University of Chicago Press.

Kuokkanen, R. 2006. Indigenous peoples on two continents: Self-determination processes in Saami and First Nation societies. Eur. Rev. Native Am. Stud. 20:25-30.

Maar, M. A., N. E. Lightfoot, M. E. Sutherland et al. 2011. Thinking outside the box: Aboriginal people's suggestions for conducting health studies with aboriginal communities. Public Health 125:747-753.

Martin, B. 2017. Methodology is content: Indigenous approaches to research and knowledge. Educ. Philos. Theory 49:1,392-1,400.

National Collaborating Centre for Aboriginal Health (NCCAH). 2013. An Overview of Aboriginal Health in Canada. Prince George, BC: National Collaborating Centre for Aboriginal Health.

Native Women's Association of Canada (NWAC). 2013. Understanding from within: Research Findings and NWAC's Contributions to Canada's National Population Health Study on Neurological Conditions (NPHSNC). https://www.nwac.ca/wpcontent/uploads/2015/05/2013-NWAC-Understanding-from-Within-Research-Findingsto-NPHSNC.pdf. 
The National Committee for Research Ethics in the Social Sciences and the Humanities (NESH). 2002. Samisk forskning og forskningsetikk. Seminarrapport [Sami Research and Research Ethics. Seminar Report]. Olso: De nasjonale forskningsetiske komiteer [The Norwegian National Research Ethics Committees].

Noonan, V. K., M. Fingas, A. Farry et al. 2012. Incidence and prevalence of spinal cord injury in Canada: A national perspective. Neuroepidemiology 38:219-226.

Parmenter, J. 2013. The meaning of Kaswentha and the Two Row Wampum Belt in Haudenosaunee (Iroquois) history: Can indigenous oral tradition be reconciled with the documentary record? J. Early Am. Hist. 3:82-109.

Porsanger, J. 2008. Ethics conduct in research involving indigenous peoples. In Ethics in Sami and Indigenous Research. Seminar Report. Karasjohka, Norway 23-24.11.2006. Sámi Instituhtta Raporta 1. (Fagtrykke Ide as, 2008) 1:24-26.

Sámediggi. 2018. Proposal for Ethical Guidelines for Sámi Health Research and Research on Sámi Human Biological Material. Karasjohka, Norway: Sámediggi.

Smylie, J., and M. Firestone. 2015. Back to basics: Identifying and addressing the underlying challenges in achieving high quality and relevant health statistics for indigenous populations in Canada. Stat. J. IAOS 31:67-87.

Schnarch, B. 2004. Ownership, control, access, and possession (OCAP) or self-determination applied to research: A critical analysis of contemporary First Nations research and some options for First Nations communities. J. Aborig. Health 1:80-95.

Tuhiwai Smith, L. 1999. Decolonizing Methodologies: Research and Indigenous Peoples. London: Zed Books. 
Tuhiwai Smith, L. 2012. Decolonizing Methodologies: Research and Indigenous Peoples, 2nd ed. London: Zed Books.

United Nations. 2007. United Nations Declaration on the Rights of Indigenous Peoples. New York: United Nations, Department of Economic and Social Affairs, Indigenous Peoples. https://www.un.org/esa/socdev/unpfii/documents/DRIPS_en.pdf.

Vogel, L. 2015. The new ethics of aboriginal health research. CMAJ 187:316-317.

Walter, M., and M. Suina. 2019. Indigenous data, indigenous methodologies and indigenous data sovereignty. Int. J. Soc. Res. Methodol. 22:233-243.

Wilk, P., A. Maltby, and J. Phillips. 2018. Unmet healthcare needs among indigenous peoples in Canada: Findings from the 2006 and 2012 Aboriginal Peoples Surveys. J. Public Health $26: 475-483$.

Wilson, S. 2008. Research Is Ceremony: Indigenous Research Methods. Winnipeg, MB: Fernwood Publishing. 
Table 1. Recommendations to Support and Promote First Nations Neurological Wellbeing in Canada

In Understanding From Within: Research findings and NWAC's contributions to Canada's

National Population Health Study on Neurological Conditions (NWAC 2013)

\section{Themes Recommendations}

\begin{tabular}{|c|c|}
\hline \multirow[t]{5}{*}{ Improved relationships } & Provision of Indigenous Patient Advocates \\
\hline & Promote the use of plain language \\
\hline & Respect for traditional ways \\
\hline & $\begin{array}{l}\text { Implement a national cultural competency program for all health } \\
\text { care providers }\end{array}$ \\
\hline & $\begin{array}{l}\text { Provision of dedicated space for spiritual ceremony and cultural } \\
\text { practices. }\end{array}$ \\
\hline \multirow[t]{4}{*}{$\begin{array}{r}\text { Indigenous-driven } \\
\text { Health Services }\end{array}$} & Bring more services to the community \\
\hline & $\begin{array}{l}\text { Indigenous health programming for Indigenous Peoples by } \\
\text { Indigenous Peoples }\end{array}$ \\
\hline & Indigenous engagement in Indigenous health policy \\
\hline & Indigenous-specific data collections \\
\hline \multirow[t]{4}{*}{ Research needs } & Indigenous men's health \\
\hline & Interactions of co-morbidities with neurological conditions \\
\hline & Aligning impacts with available supports \\
\hline & $\begin{array}{l}\text { Examine how Indigenous-specific risk factors differ from } \\
\text { mainstream }\end{array}$ \\
\hline
\end{tabular}

Pre-print version. Visit http://digitalcommons.wayne.edu/humbiol/ after publication to acquire the final version. 
Examine relationship between risk factors and prevalence (social determinants of health perspective to ensure wholistic health and well-being is considered)

Examine conditions that cause higher morbidity rates

Relevance, subpopulations, violence

Pre-print version. Visit http://digitalcommons.wayne.edu/humbiol/ after publication to acquire the final version. 


\section{Figure Captions}

Figure 1. Indigenous Epistemology Medicine Wheel-based Research Framework. Wholistic health involves the physical, mental, emotional and spiritual dimensions (triangles). Research processes guided by these principles are indicated in boxes. Researchers must make iterative journeys around the wheel to remain ethically engaged with community (blue text). Initial concerns of collaborators are identified in circles.

Figure 2. The Two Row Wampum Belt: An Akwesasne Tradition of the Vessel and Canoe. (Bonaparte, 2005). Available at: http://wampumchronicles.com/tworowwampumbelt.html. 


\section{Figure 1.}

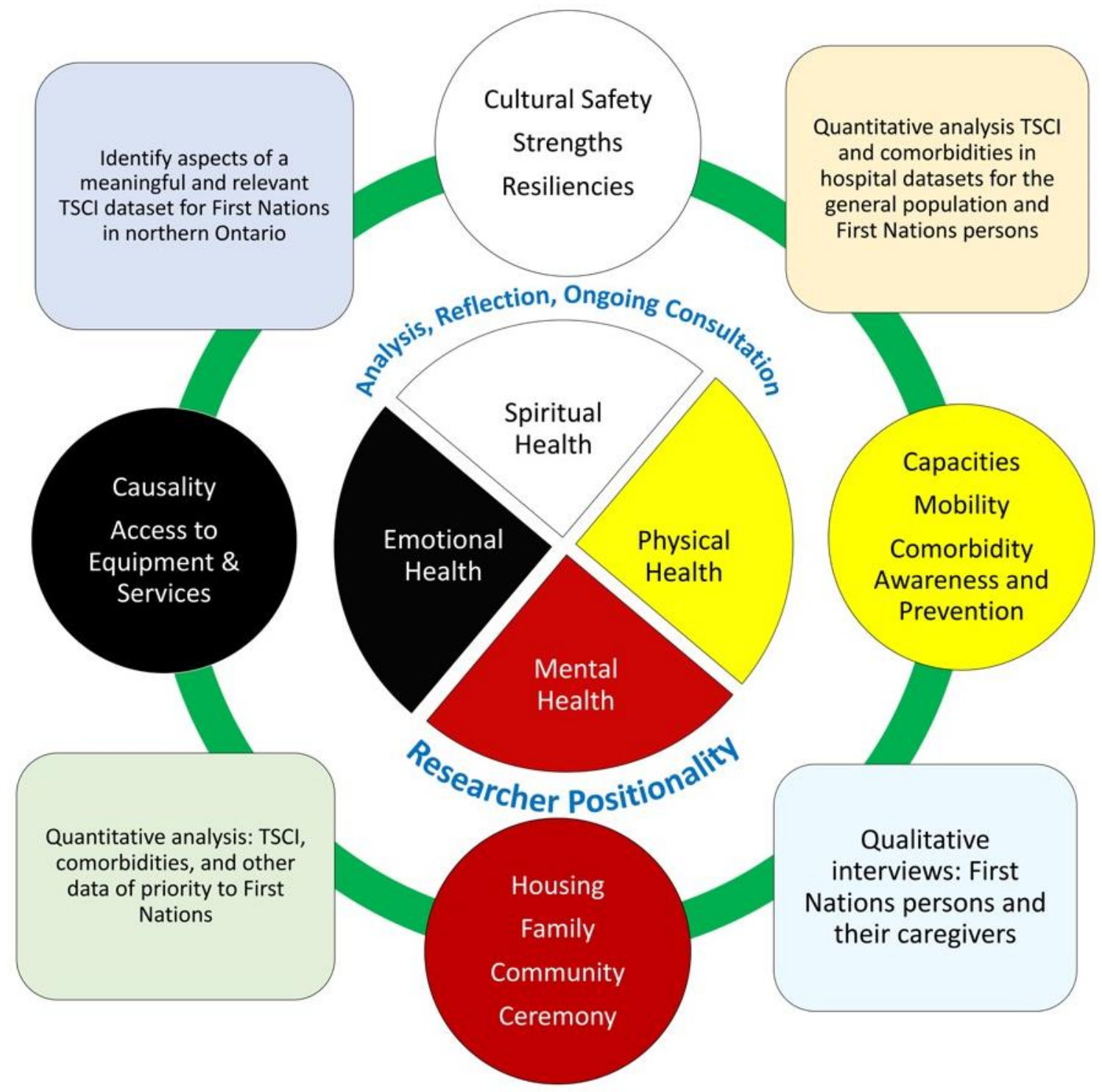

Pre-print version. Visit http://digitalcommons.wayne.edu/humbiol/ after publication to acquire the final version. 


\section{Figure 2.}

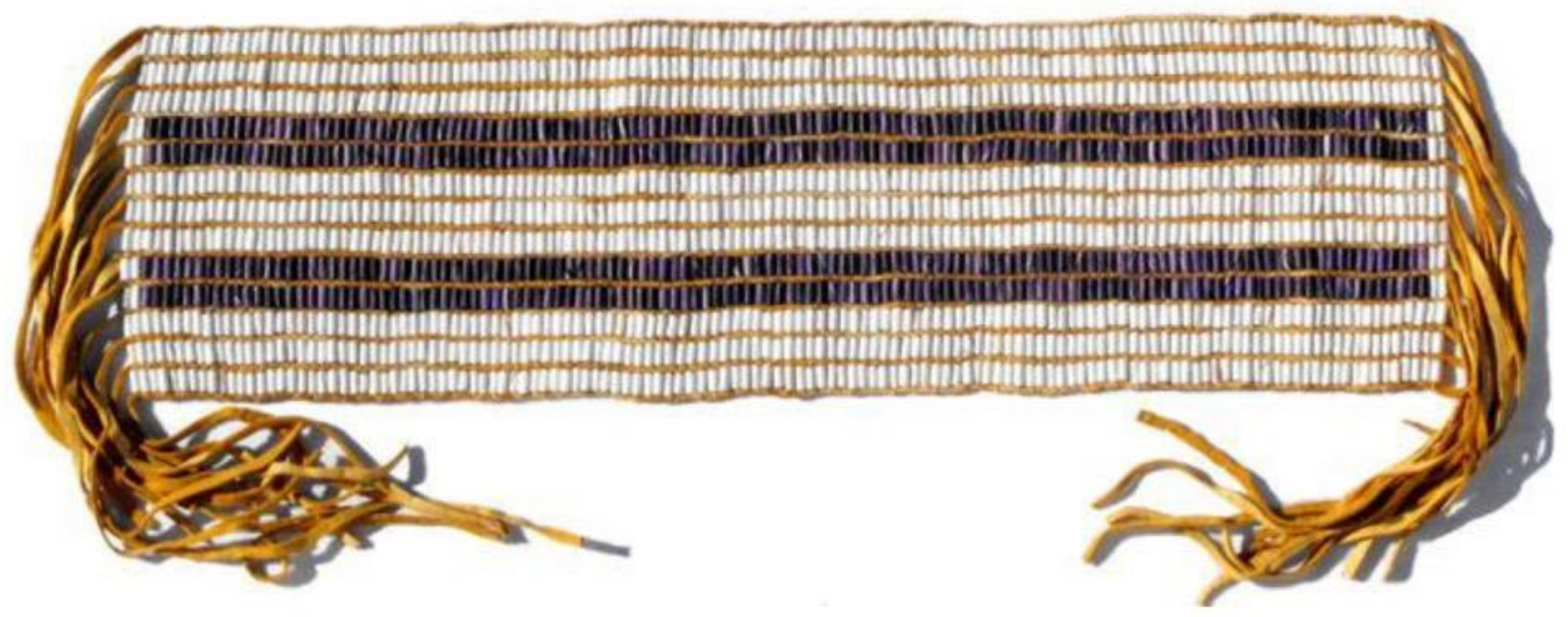

Pre-print version. Visit http://digitalcommons.wayne.edu/humbiol/ after publication to acquire the final version. 